\title{
Increased carotid intima-media thickness as a predictor for abnormal myocardial perfusion by dobutamine stress echocardiography in patients with diabetes mellitus type 2
}

\section{Mohammed Othman Metwally ${ }^{(1)}$, Eman Mahmoud Abdelfattah ${ }^{(2)}$, Mohammed Gamal Mousa $^{(3)}$, Khaled Ahmed Elkhashab ${ }^{(4)}$}

(1) Cardiology department, Faculty of Medicine, Fayoum University.

(2) Lecturer of Cardiology, Faculty of Medicine, Fayoum University.

(3) Lecturer of Cardiology, Faculty of Medicine, Fayoum University.

(4) Professor of Cardiology, Faculty of Medicine, Fayoum University.

\section{Corresponding author: Dr. Mohammed Othman Metwally}

E-mail: mohammedosman32@yahoo.com

Tel: 01005063030

\begin{abstract}
Background: Coronary artery disease (CAD) remains a leading cause of death among patients with diabetes mellitus (DM). Hence, screening tests for early diagnosis of CAD may lead to early treatment and therefore improved outcomes.
\end{abstract}

Aim of the work: The aim of this study was to correlate myocardial perfusion abnormality by dobutamine stress echocardiography to carotid intima-media thickness in type 2 diabetic patients free from cardiac symptoms.

Subjects and methods: Fifty type 2 diabetic patients with or without other risk factors (case group) and twenty-five nondiabetic patients (control group) were included in this study. Full history taking, complete clinical examination, ECG, assessment of carotid intima-media thickness (CIMT) and carotid plaques by carotid ultrasonography and myocardial perfusion imaging by dobutamine stress echocardiography (DSE) were performed for all subjects.

Results: The prevalence of abnormal myocardial perfusion by DSE in asymptomatic diabetic patients was $8 \%$. There was positive correlation between CIMT and duration of DM and age. In relation to wall motion score index (WMSI), there was significant elevation in CIMT $(p=0.022)$ and carotid plaque $(p=0.028)$ in the patients with positive stress study.

Conclusion: The findings of this study show that increased CIMT and carotid plaque were significantly related to the presence and extent of abnormal myocardial perfusion, it is reasonable to recommend using CIMT to 
identify asymptomatic patients with type 2 diabetes mellitus at higher risk for CAD and indirect predictor for cardiovascular events.

\section{Keywords:}

Carotid intima media thickness, dobutamine stress echocardiography, asymptomatic diabetic patients

\section{Introduction}

Diabetes is a fast-growing health problem in Egypt with a significant impact on morbidity and mortality. Currently, the prevalence of type 2 diabetes (T2DM) in Egypt is around 15.6\% of all adults aged 20 to 79 [1]. Diabetes mellitus is also a powerful risk factor for coronary artery disease and carotid atherosclerosis [2].

Silent myocardial ischemia (SMI) is more common in diabetic patients with a prevalence about $15 \%$ to $22 \%$ [3]. Coronary artery disease (CAD) is usually a late diagnosis in diabetic patients and the disease is usually more advanced at that time [4].

Screening tests for early diagnosis of CAD may lead to early treatment and therefore improved outcomes. So, many studies were conducted searching for a valid and reliable screening method. However, no sufficient evidence could be concluded from these studies which make an open field for more research [5].

Several ways for screening SMI were tried to predict abnormal myocardial perfusion such as exercise or pharmacological stress tests, carotid intima media thickness, coronary artery calcium, Radionuclide Imaging and CT coronary angiography [6].

Carotid intima media thickness (CIMT) is one method of calculating plaque burden by assessing the level of arterial thickening present. CIMT used as a noninvasive marker of atherosclerotic disease was also linked to an increased risk of subsequent cardiovascular events [7].

Dobutamine stress echocardiography (DSE) is a well-established clinical tool, both for the diagnostic and prognostic assessment of patients with known or suspected coronary artery disease [8].

The aim of this study was to correlate myocardial perfusion abnormality by dobutamine stress echocardiography to carotid intima-media thickness in type 2 diabetic patients free from cardiac symptoms. 


\section{Subjects and Methods}

This study was conducted on fifty type 2 diabetic patients with or without other risk factors (case group) and twenty-five sex and age matched non-diabetic patients (control group). They were recruited from outpatient clinic of Internal Medicine Department, Fayoum University Hospitals.

The study was approved by the Faculty of Medicine Research Ethical Committee and written informed consent was obtained from all study participants.

\section{Inclusion criteria:}

- Age (between 40 and 70 years).

- Long standing duration of type 2 diabetes (at least more than 5 years).

- Absence of clinical or electrocardiogram (ECG) findings of ischemia.

\section{Exclusion criteria:}

- Patients known to have ischemic heart disease (IHD).

- Patients with previous neck irradiation.

- Patients with history of carotid surgery or cerebrovascular accident.

- Any neck deformity interfering with carotid ultrasonography.

- Patient with echocardiographic poor window.

- Patient with regional wall motion abnormalities at resting echocardiography.
- Patient with dyssynchronization of cardiac muscle with echocardiography.

Full history taking and complete physical examination were done with special emphasis on disease duration and treatment, smoking and hypertension.

A 12 lead surface ECG was performed to identify and exclude old myocardial infarction (pathological Q waves), classic ischemic ST-T wave changes, left ventricular hypertrophy, conduction defects and non-specific changes.

\section{Ultrasonographic evaluation of the carotid} arteries:

Carotid intima-media thickness (CIMT) and carotid plaques were assessed by ultrasonography of both the right and left common carotid arteries using high-resolution B-mode ultrasonography (Logic P5):

\section{1- Carotid intima-media thickness (CIMT) measurement:}

Subjects were scanned in the supine position with the shoulder placed on a pillow and neck extended, the head was turned about $45^{\circ}$ away from the side being scanned. On longitudinal 2D ultrasound image of the carotid artery, the 
near wall and the far wall are displayed as 2 echogenic lines (the adventitia and intima) that are separated by the hypoechoic media. The distance between the leading edge of the first bright line of the far wall (lumen-intima interface) and the leading edge of the second bright line (media-adventitia interface) is defined as the CIMT. Values of more than 0.9 $\mathrm{mm}$ or over the 75 th percentile are considered abnormal.

\section{2- Carotid plaques assessment:}

Plaque was defined as a localized protrusion of the vessel wall, which extended into the lumen ( $\geq 1.5 \mathrm{~mm}$ ) or had a thickness exceeding the intima-media thickness (IMT) of the adjacent portion of the vessel wall by $>50 \%$. This was measured bilaterally by using linear array transducer scanning of common and internal carotid arteries.

\section{Dobutamine stress echocardiography (DSE):}

DSE was performed according to standard protocol. Dobutamine was injected initially intravenously (using infusion pump) at a dose of $10 \mu \mathrm{g} / \mathrm{kg} / \mathrm{min}$ then increased by $10 \mu$ $\mathrm{g} / \mathrm{kg} / \mathrm{min}$ every 3-5 minutes until a peak dose of $40 \mu \mathrm{g} / \mathrm{kg} / \mathrm{min}$ and a target heart rate of $85 \%$ of age-predicted maximum heart rate were acheived . Atropine (up to a maximum of 1-2 $\mathrm{mg}$ ) was used to achieve the target heart rate if not achieved with dobutamine. Vital signs, symptoms and ECG were monitored with each infusion stage and throughout the test.

Echocardiographic digital images were acquired continuously during the dobutamine infusion in the long parasternal-long and apicalshort 4- and 2-chamber views using Philips Epic 7C echocardiography machine. Regional wall motion was analyzed by determining the wall motion score index (WMSI) with a model that divides the left ventricular myocardium into 16 segments and assigns a wall motion score of 1 to 4 to each segment $(1=$ normal or hyperkanetic, $2=$ hypokensia , $3=$ akensia , $4=$ dyskinetic).

Abnormal wall motion of the anterior septal, medial septal, apical, and anterior segments indicates disease of the left anterior descending coronary artery, whereas abnormal motion of the lateral and posterior segments indicates diseased circumflex artery and abnormal motion of the inferior and basal septal segments indicates right coronary artery lesions. 
End points for stopping the test were achievement of $85 \%$ of age-predicted maximum heart rate, development of sustained ventricular tachycardia, decrease in absolute or relative $\mathrm{SBP}$ by more than $30 \mathrm{~mm} \mathrm{Hg}$ and development of a new wall motion abnormality Heart rate, blood pressure, and ECG were continuously monitored for 10 to 15 minutes or until they return to the baseline state.

\section{Statistical methods:}

The collected data were organized, tabulated and statistically analyzed using SPSS software statistical computer package version 22 (SPSS
Inc, USA). For quantitative data, the mean, standard deviation (SD), and range were calculated. Independent t-test or MannWhitney-U test, as appropriate, was used in comparing between two groups. Qualitative data were presented as number and percentages, chi square $\left(\chi^{2}\right)$ was used as a test of significance. Pearson correlation was run to identify relation between CIMT and study parameters. For interpretation of results of tests of significance, significance was adopted at $\mathrm{p}<$ 0.05 .

\section{Results}

Demographic characteristics of both study groups are shown in table 1 . The mean age of case group was $55.5 \pm 5.7$ while that of control group was $55.4 \pm 5$. In the case group $42 \%$ were males and $58 \%$ were females, while in control group 52\% were males and $48 \%$ were females.

Table 2 and figure 1 show risk factors among study groups. The proportion of smoking was statistically significantly higher in control group than in case group (40\% vs. $18 \%$ ), $\mathrm{p}=0.039$. Percentage of hypertension was also statistically significantly higher in controls than in cases $(72 \%$ vs. $40 \%), p=0.009$. Although mean \pm SD duration of hypertension was higher in controls $(8.6 \pm 3)$ than cases $(6.8 \pm 4.6)$, it was not statistically significant, $\mathrm{p}=0.228$. 
Type of treatment and diabetes duration among case group are shown in table $3.66 \%$ of diabetic patients were treated by oral hypoglycemic drugs while $34 \%$ of were treated by insulin. Mean \pm SD of diabetes duration was 8.5 \pm 3.2 .

Echocardiographic characteristics of study groups are shown in table 4. Abnormal wall motion score index (WMSI) distribution was $8 \%$ in case group and zero\% in control group. There was statistically significant difference between cases and controls as regards stress ejection fraction $(\mathrm{EF}) \mathrm{p}=0.003$. On the other hand, there was no significant difference between cases and controls as regards other parameters $\mathrm{p}>0.05$.

Carotid intima-media thickness (CIMT) in both study groups is shown in table 5. There was no statistically significant difference between cases and controls as regards mean right carotid intima-media thickness (CIMTR) $\mathrm{p}=0.707$ and mean left carotid intimamedia thickness (CIMTL) $\mathrm{p}=0.645$.

Plaque distribution among study groups is shown in table 6 . There was no a statistically significant difference between cases and controls as regards presence of plaque $(\mathrm{p}=1.000)$.

Table 6 and figure 2 show relation between carotid intima-media thickness (CIMT) and wall motion score index (WMSI) in case group. Right intima-media thickness (CIMTR) mean value was significantly higher in cases showing abnormal WMSI (positive stress test) compared to cases with normal WMSI (negative stress test) ( $\mathrm{p}$ value $=0.022$ ). While there was no difference between the two groups as regards left intima-media thickness (CIMTL) mean value $(\mathrm{p}=0.120)$.

Relation between plaque and wall motion score index (WMSI) in case group is shown in table 7 and figure 3. Percentage of cases with plaque was significantly higher in cases showing abnormal WMSI (positive stress test) compared to cases with normal WMSI (negative stress test $)(\mathrm{p}=0.028)$. 
Correlation between carotid intima-media thickness (CIMT) and other parameters in case group is shown in table 8. Right carotid intima-media thickness (CIMTR) was positively correlated with age $(\mathrm{r}=0.365)$, duration of diabetes mellitus $(\mathrm{r}=0.414)$, and wall motion score index (WMIS) $(\mathrm{r}=0.301)$. Left carotid intima-media thickness (CIMTL) was positively correlated with duration of diabetes mellitus ( $\mathrm{r}=0.403)$ only.

Table (1): Demographic characteristics of both study groups

\begin{tabular}{|c|c|c|c|}
\hline Variables & $\begin{array}{l}\text { Cases } \\
(\mathrm{N}=50)\end{array}$ & $\begin{array}{c}\text { Controls } \\
(\mathrm{N}=\mathbf{2 5})\end{array}$ & p-value \\
\hline \multicolumn{4}{|l|}{ Age (years) } \\
\hline Mean \pm SD & $55.5 \pm 5.7$ & $55.4 \pm 5$ & 0.976 \\
\hline \multicolumn{4}{|l|}{ Sex } \\
\hline Male (\%) & $21(42 \%)$ & $13(52 \%)$ & \multirow{2}{*}{0.412} \\
\hline Female (\%) & $29(58 \%)$ & $12(48 \%)$ & \\
\hline
\end{tabular}

Table (2): Risk factors among study groups

\begin{tabular}{|c|c|c|c|c|c|}
\hline \multirow{2}{*}{ Variable } & \multicolumn{2}{|c|}{$\begin{array}{c}\text { Cases } \\
(\mathrm{N}=\mathbf{5 0})\end{array}$} & \multicolumn{2}{|c|}{$\begin{array}{c}\text { Controls } \\
(\mathrm{N}=25) \\
\end{array}$} & \multirow{2}{*}{ p-value } \\
\hline & $\mathbf{N}$ & $\%$ & $\mathbf{N}$ & $\%$ & \\
\hline \multicolumn{6}{|l|}{ Smoking } \\
\hline Smoker & 9 & $18.0 \%$ & 10 & $40.0 \%$ & \multirow{2}{*}{0.039} \\
\hline Non-smoker & 41 & $82.0 \%$ & 15 & $60.0 \%$ & \\
\hline \multicolumn{6}{|l|}{ HTN } \\
\hline Present & 20 & $40.0 \%$ & 18 & $72.0 \%$ & \multirow{2}{*}{0.009} \\
\hline Absent & 30 & $60.0 \%$ & 7 & $28.0 \%$ & \\
\hline \multicolumn{6}{|l|}{ Duration of HTN } \\
\hline Mean \pm SD & \multicolumn{2}{|c|}{$6.8 \pm 4.6$} & \multicolumn{2}{|c|}{$8.6 \pm 3$} & 0.228 \\
\hline
\end{tabular}

HTN: hypertension

Table (3): Type of treatment and diabetes duration among case group 


\begin{tabular}{|c|c|c|}
\hline \multirow{2}{*}{ Variable } & \multicolumn{2}{|c|}{$\begin{array}{c}\text { Cases } \\
\text { (N=50) }\end{array}$} \\
\cline { 2 - 3 } & $\mathbf{N}$ & $\%$ \\
\hline \hline Anti-diabetic drugs & 33 & $66.0 \%$ \\
\hline Oral & 17 & $34.0 \%$ \\
\hline Insulin & \multicolumn{2}{|}{} \\
\hline \hline Duration of DM & \multicolumn{2}{|c|}{$8.5 \pm 3.2$} \\
\hline Mean \pm SD & \multicolumn{2}{|c|}{} \\
\hline
\end{tabular}

DM: diabetes mellitus

Table 4: Echocardiographic characteristics in both study group

\begin{tabular}{|c|c|c|c|c|c|}
\hline \multirow{3}{*}{ Variable } & \multicolumn{2}{|c|}{$\begin{array}{c}\text { Cases } \\
(\mathrm{N}=50)\end{array}$} & \multicolumn{2}{|c|}{$\begin{array}{c}\text { Controls } \\
(\mathrm{N}=25)\end{array}$} & \multirow{3}{*}{ p-value } \\
\hline & Mean & SD & Mean & SD & \\
\hline & \multicolumn{2}{|c|}{ Range } & \multicolumn{2}{|c|}{ Range } & \\
\hline \multirow{2}{*}{ EF rest } & 59.1 & 2.3 & 60.7 & 3.3 & \multirow{2}{*}{0.069} \\
\hline & \multicolumn{2}{|c|}{$(55-65)$} & \multicolumn{2}{|c|}{$(56-70)$} & \\
\hline \multirow{2}{*}{ EF stress } & 64.6 & 4.1 & 67.6 & 3.2 & \multirow{2}{*}{$0.003^{*}$} \\
\hline & \multicolumn{2}{|c|}{$(50-72)$} & \multicolumn{2}{|c|}{$(62-75)$} & \\
\hline \multirow{2}{*}{ WMSI } & 16.3 & 1.1 & 16 & 0 & \multirow{2}{*}{0.149} \\
\hline & \multicolumn{2}{|c|}{$(16-22)$} & \multicolumn{2}{|c|}{$(16-16)$} & \\
\hline Variable & $\mathbf{N}$ & $\%$ & $\mathbf{N}$ & $\%$ & p-value \\
\hline \multicolumn{6}{|l|}{ WMSI } \\
\hline Abnormal & 4 & $8 \%$ & 0 & $0 \%$ & \multirow{2}{*}{0.294} \\
\hline Normal & 46 & $92 \%$ & 25 & $100 \%$ & \\
\hline
\end{tabular}

EF: ejection fraction, WMSI: wall motion score index 
Table (5): Carotid intima-media thickness (CIMT) in both study groups

\begin{tabular}{|c|c|c|c|c|c|}
\hline \multirow{3}{*}{ Variable } & \multicolumn{2}{|c|}{$\begin{array}{c}\text { Cases } \\
(\mathrm{N}=50)\end{array}$} & \multicolumn{2}{|c|}{$\begin{array}{c}\text { Controls } \\
(\mathrm{N}=25)\end{array}$} & \multirow{3}{*}{ p-value } \\
\hline & Mean & SD & Mean & SD & \\
\hline & \multicolumn{2}{|c|}{ Range } & \multicolumn{2}{|c|}{ Range } & \\
\hline \multirow{2}{*}{ CIMTR } & 1 & 0.2 & 1 & 0.2 & \multirow{2}{*}{0.707} \\
\hline & \multicolumn{2}{|c|}{$(0.5-1.7)$} & \multicolumn{2}{|c|}{$(0.7-1.4)$} & \\
\hline \multirow{2}{*}{ CIMTL } & 0.9 & 0.2 & 0.9 & 0.2 & \multirow{2}{*}{0.645} \\
\hline & \multicolumn{2}{|c|}{$(0.6-1.7)$} & \multicolumn{2}{|c|}{$(0.7-1.3)$} & \\
\hline
\end{tabular}

CIMTR: right carotid intima-media thickness, CIMTL: left carotid intima-media thickness

Table (6): Plaque distribution among study groups

\begin{tabular}{||c|c|c|c|c|c|}
\hline \multirow{2}{*}{ Variable } & \multicolumn{2}{|c|}{$\begin{array}{c}\text { Case } \\
(\mathbf{N = 5 0 )}\end{array}$} & \multicolumn{2}{c|}{$\begin{array}{c}\text { Control } \\
(\mathbf{N = 2 5})\end{array}$} & \multirow{2}{*}{ p-value } \\
\cline { 2 - 5 } & $\mathbf{N}$ & $\%$ & $\mathbf{N}$ & $\%$ & \\
\hline Plaque & 4 & $8 \%$ & 2 & $8 \%$ & \multirow{2}{*}{1.000} \\
\hline Present & 46 & $92 \%$ & 23 & $92 \%$ & \\
\hline Absent & 46 & \\
\hline
\end{tabular}

Table (7): Relation between CIMT and WMSI in case group

\begin{tabular}{|c|c|c|c|c|c|}
\hline \multirow{3}{*}{ Variable } & \multicolumn{2}{|c|}{$\begin{array}{c}\text { Abnormal WMSI } \\
(\mathrm{N}=4)\end{array}$} & \multicolumn{2}{|c|}{$\begin{array}{c}\text { Normal WMSI } \\
(\mathrm{N}=46)\end{array}$} & \multirow{3}{*}{ p-value } \\
\hline & Mean & SD & Mean & SD & \\
\hline & \multicolumn{2}{|c|}{ Range } & \multicolumn{2}{|c|}{ Range } & \\
\hline \multirow{2}{*}{ CIMTR } & 1.2 & 0.2 & 0.9 & 0.2 & \multirow{2}{*}{$0.022^{*}$} \\
\hline & \multicolumn{2}{|c|}{$(1-1.5)$} & \multicolumn{2}{|c|}{$(0.5-1.7)$} & \\
\hline \multirow{2}{*}{ CIMTL } & 1.1 & 0.2 & 0.9 & 0.2 & \multirow{2}{*}{0.120} \\
\hline & \multicolumn{2}{|c|}{$(0.8-1.3)$} & \multicolumn{2}{|c|}{$(0.6-1.7)$} & \\
\hline
\end{tabular}

WMSI: wall motion score index, CIMTR: right carotid intima-media thickness, CIMTL: left carotid intima-media thickness 
Table (8): Relation between plaque and WMSI in case group

\begin{tabular}{|c|c|c|c|c|c|}
\hline \multirow{2}{*}{ Variable } & \multicolumn{2}{|c|}{$\begin{array}{c}\text { Abnormal WMSI } \\
(\mathrm{N}=4)\end{array}$} & \multicolumn{2}{|c|}{$\begin{array}{c}\text { Normal WMSI } \\
(\mathrm{N}=46)\end{array}$} & \multirow{2}{*}{ p-value } \\
\hline & $\mathbf{N}$ & $\%$ & $\mathbf{N}$ & $\%$ & \\
\hline \multicolumn{6}{|l|}{ Plaque } \\
\hline Present & 2 & $50 \%$ & 2 & $4.3 \%$ & \multirow{2}{*}{$0.028^{*}$} \\
\hline Absent & 2 & $50 \%$ & 44 & $95.7 \%$ & \\
\hline
\end{tabular}

WMSI: wall motion score index

Table (9): Correlation between CIMT and other parameters in case group

\begin{tabular}{|l|c|c|c|}
\hline & & CIMTR & CIMTL \\
\hline \multirow{2}{*}{ Age (years) } & $\mathbf{R}$ & $\mathbf{0 . 3 6 5}$ & 0.210 \\
\cline { 2 - 4 } & p-value & $\mathbf{0 . 0 0 9}{ }^{*}$ & 0.142 \\
\hline \multirow{3}{*}{ Duration of DM } & $\mathbf{R}$ & $\mathbf{0 . 4 1 4}$ & $\mathbf{0 . 4 0 3}$ \\
\cline { 2 - 4 } & p-value & $\mathbf{0 . 0 0 3}{ }^{*}$ & $\mathbf{0 . 0 0 4}$ \\
\hline \multirow{2}{*}{ Duration of } & $\mathbf{R}$ & 0.143 & 0.060 \\
\cline { 2 - 4 } & p-value & 0.546 & 0.800 \\
\hline \multirow{2}{*}{ WMSI } & R & $\mathbf{0 . 3 0 1}$ & 0.225 \\
\cline { 2 - 4 } & p-value & $\mathbf{0 . 0 3 4}$ & 0.116 \\
\hline
\end{tabular}

CIMTR: right carotid intima-media thickness, CIMTL: left carotid intima-media thickness, DM: diabetes mellitus, HTN= hypertension, WMSI: wall motion score index 


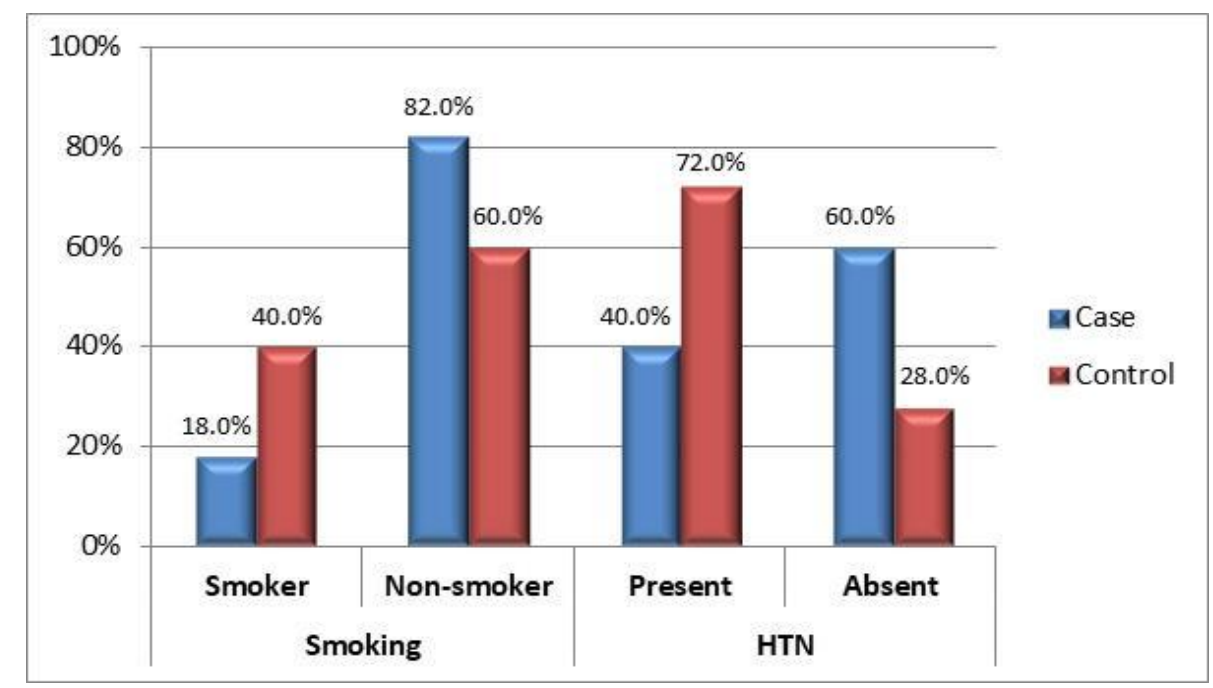

Figure (1): Risk factors among study groups

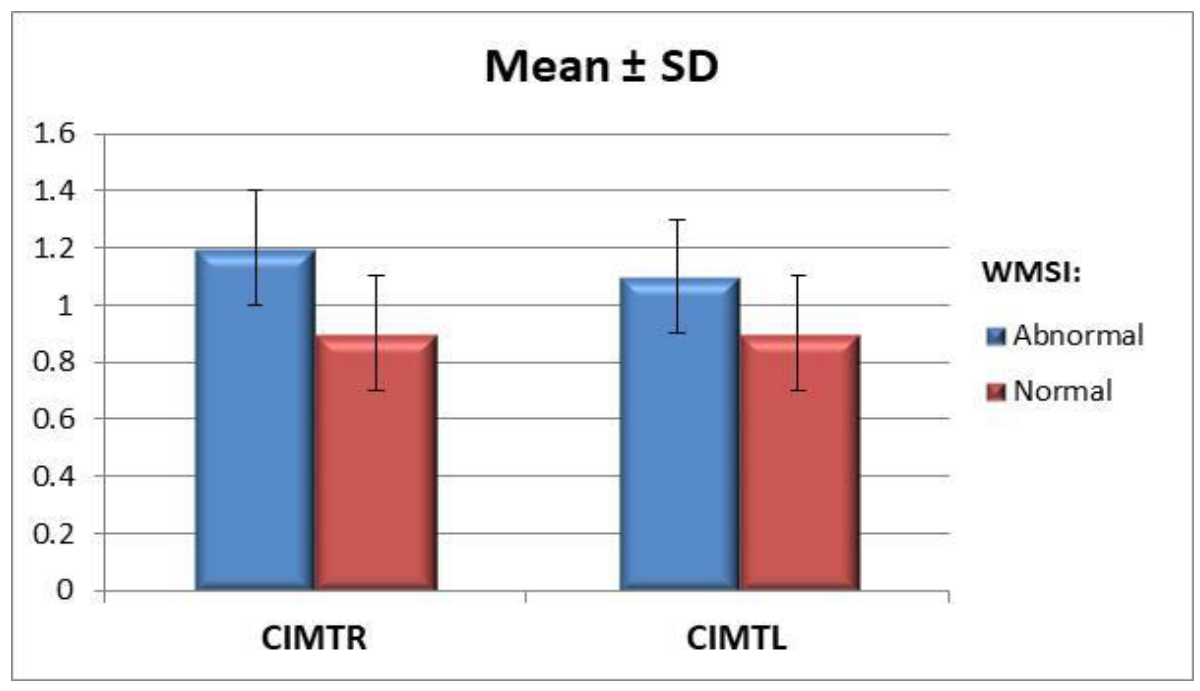

Figure (2): Relation between CIMT and WMSI in case group

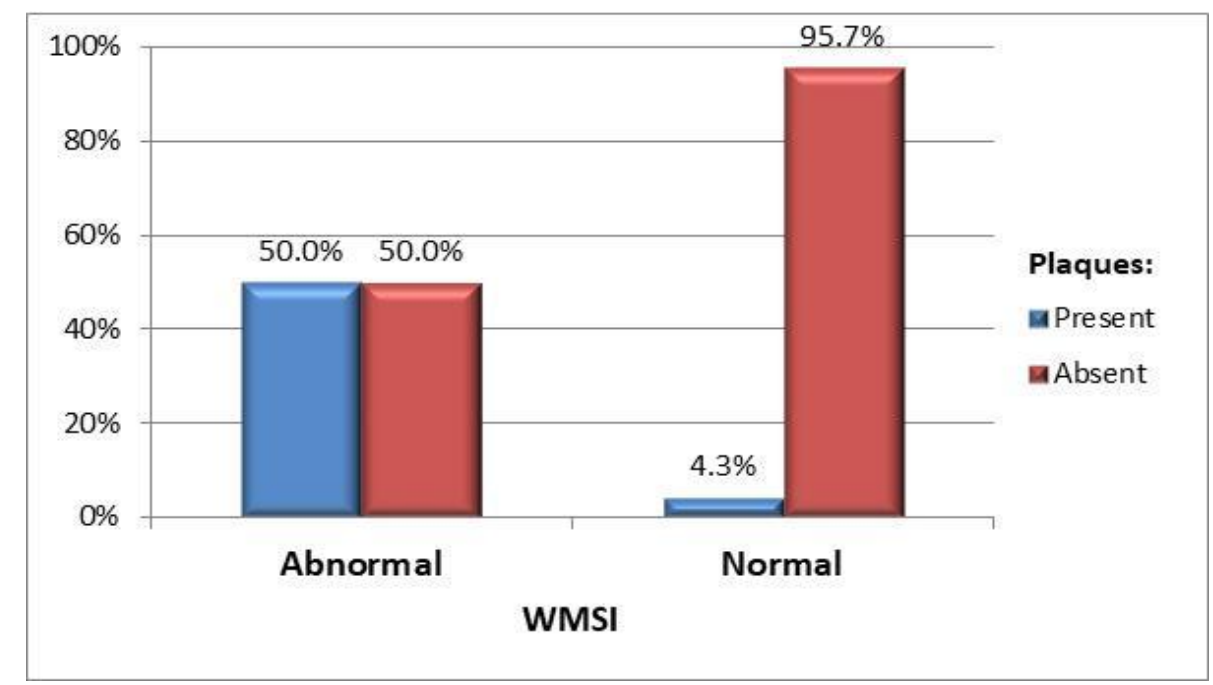




\section{Figure (3): Relation between plaque and WMSI in case group}

\section{Discussion}

Coronary artery disease (CAD) remains a leading cause of death among patients with diabetes mellitus (DM). However, many patients with diabetes who have CAD are asymptomatic and may sustain a myocardial infarction as their presenting symptom of CAD [9]. Moreover, when the diagnosis of CAD is made, the prognosis of diabetic patients is worse than that of non-diabetic patients [10]. Since an early detection of the disease may potentially impact therapeutic strategies and prevents cardiac events, there has long been interest in the screening of diabetic patients for the presence of asymptomatic CAD.

Assessment of coronary intima-media thickening (CIMT) has been previously proposed for this purpose [11]. Moreover, the truly noninvasive, inexpensive, and radiationfree nature of CIMT may represent an important advantage over other suggested screening techniques such as coronary calcium scoring [12]. However, the relation of CIMT with CAD has not been fully established in asymptomatic diabetic patients. The aim of this work was to correlate myocardial perfusion abnormality by dobutamine stress echocardiography to carotid intima-media thickness in type 2 diabetic patient free from cardiac symptoms.

In this study, $8 \%$ of asymptomatic diabetic patients (case group) had an abnormal stress myocardial perfusion study indicative of cardiovascular disease. In (Milan Study) on Atherosclerosis and Diabetes [13], exercise electrocardiography was used in asymptomatic patients with diabetes as an initial test to select candidates for stress myocardial perfusion imaging. Possibly because of the low accuracy of exercise ECG for detection CAD, the overall prevalence of observed silent CAD was low: 97 (13\%) of 735 enrolled patients had an abnormal exercise test that was confirmed in only $52 \quad(53 \%$ by myocardial perfusion imaging), yielding an overall prevalence of silent ischemia of only $(6 \%)$.

Equally negative results were found in a subsequent large study examining the benefit of screening for CHD in 900 diabetic patients (type 1 or 2) without prior CVD (FACTOR-64 trial) [14]. In contrast to the DIAD and 
DYNAMIT trials in which screening of asymptomatic patients with T2D was based on the identification of significant myocardial ischemia using a functional stress test, the FACTOR-64 trial, conducted in the United States, evaluated the extent and severity of coronary atherosclerosis using an anatomic test (coronary computed tomography angiography (CCTA). Also, contrary to the previous studies, it provided specific treatment guidance to the physicians, based on the $\mathrm{CT}$ results. Among patients randomized to CCTA screening, the prevalence of mild, moderate, and severe CHD was $31 \%, 46 \%$, and $12 \%$, respectively. After a mean follow-up of 4 years, there was no significant difference in the primary endpoint (composite of all-cause mortality, nonfatal MI, or unstable angina) following screening with CCTA (6.2\% versus $7.6 \%$ without screening; HR: 0.8; $95 \% \mathrm{CI}$ : $0.5-1.3)$.

Although several studies have described the prevalence of myocardial ischemia in patients with type 2 diabetes mellitus, only a limited number of studies have prospectively included truly asymptomatic patients with diabetes. These prospective studies have shown a prevalence of silent myocardial ischemia ranging from (15\% to $22 \%)$ [3]. One of them the (DIAD study) that evaluated the prevalence of silent ischemia in522 asymptomatic patients with two or more risk factors, using gated technetium-99msestamibi single photon emission computed tomography imaging. The authors noted a relatively high percentage (22\%) of abnormal myocardial perfusion studies [15]. The discrepancy in the prevalence of silent myocardial ischemia between the present study and the DIAD trial can be explained by number of patients enrolled in the study and the sensitivity of the screening method used.

In this study, there was positive correlation between CIMT and duration of DM and age, but there was no significant correlation between CIMT and duration of HTN or smoking.

In a study done by Mitsushashi et al. 2002, reported that existence of any of these risk factors is associated with higher CIMT and incidence of existing carotid plaques [16].The results of Cheng et al. 2012, showed that the presence of only one risk factor was associated 
with a significant increase in IMR and IMT [17].

Difference could be explained also by smaller number of patients enrolled in the present study compared to 522 patients included in the DIAD trial [15].

Studies found that arterial hypertension has the highest association with CIMT. At the same time, some population-based studies have confirmed an association between CIMT and arterial hypertension as well as other traditional risk factors for atherosclerosis such as smoking, dyslipidemia and hyperglycemia [18].

In the current study, the CIMT was significantly elevated in relation to WMSI $(\mathrm{P}$ value $=0.022)$ in the patients with positive stress study.

In a study by Kafetzakis et al. 2005, there was positive correlation of CIMT and significant coronary artery disease as assessed by coronary

angiography having $>50 \%$ diameter stenosis. There was positive association with increased number of coronary artery involved [19].
558 patients were evaluated in a study by Kablak-Ziemcicka et al. 2004 who found that an individual with CIMT value of $\quad>1.15 \quad \mathrm{~mm} \quad$ had a 94\% chance of having significant CAD [20].

Holland et al. 2009 reported that a maximal CIMT value of $0.956 \mathrm{~mm}$ had $85.7 \%$ sensitivity and $85.1 \%$ specificity to predict angiographic CAD [21].

There are few prospective studies that have demonstrated this relationship in a DM population lacking CAD symptoms. The American College of Cardiology/American Heart Association guidelines for assessment of cardiovascular risk in asymptomatic intermediate risk group recommends use of CAC screening and carotid screening (IIa recommendation). It is therefore paramount to identify the subgroup of this population who are at risk of cardiovascular events [22].

In this study, plaque was significantly elevated in relation to WMSI $\quad(p=0.028)$ in the patients with positive stress study.

The presence of carotid plaque showed a strong and persistent relationship with extensive coronary artery calcification. These findings 
are consistent with a previous study by Oei et al. 2002. Their study of 2013 patients found a linear and graded relationship between CAC and carotid plaque using CAC scans and carotid ultrasound [23].

The same correlation is seen in the study by Ahmadvazir et al. 2014, the presence of carotid plaque appeared to increase the predictive power of the stress test for diagnosing coronary artery disease [24].

Hallerstam et al.2004 reported a correlation between carotid atherosclerosis and the extent and severity of CAD [25].

The limitations of this study are the limited number of patients that could limit the strength of the conclusion rationalized from the study, not all risk factors were included in the study and detection of the coronary lesion in the coronary arteries by coronary angiography was not performed to all patients.

In conclusion, despite the low prevalence of silent ischemia (8\%), Increased CIMT was significantly related to the presence and extent of abnormal myocardial perfusion. Carotid plaque was significantly related to the presence of abnormal myocardial perfusion. Assessment of CIMT is useful to identify asymptomatic patients with type 2 diabetes at higher risk for $\mathrm{CAD}$ and indirect predictor for $\mathrm{CV}$ events.

\section{References}

1) Whiting DR, Guariguata L, Weil C, et al. IDF Diabetes Atlas: Global estimates of the prevalence of diabetes for 2011 and 2030. Diabetes Res Clin Pract 2011; 94 (3): 311321.

2) Hajar R. Diabetes as "Coronary Artery Disease Risk Equivalent": A Historical Perspective. Heart Views 2017; 18(1): 34-37.

3) Anand D, Lim E, Hopkins D, et al. Risk stratification in uncomplicated type 2 diabetes: prospective evaluation of the combined use of coronary artery calcium imaging and selective myocardial perfusion scintigraphy. Eur Heart J 2006; 27(6):713- 721.

4) Turrini F, Scarlini S, Mannucci C, et al. Does coronary Atherosclerosis Deserve to be diagnosed early in Diabetic patients. The DADDY-D trial. Screening diabetic patients for unknown coronary disease. Eur J Intern Med 2015; 26(6):407-413.

5) De Lorenzo A. Screening for silent coronary artery disease in diabetics-or not? Curr Diabet Rev 2015; 11(2):98-101.

6) Budoff MJ, Raggi P, Beller GA, et al. Noninvasive cardiovascular risk assessment of the asymptomatic diabetic patient: the imaging 
council of the American College of Cardiology. JACC Cardiovasc Imaging 2016; 9(2):176-192.

7) Carpenter M, Sinclair H, Kunadian V. Carotid intima media thickness and its utility as a predictor of cardiovascular disease: a review of evidence. Cardiol Rev 2016; 24(2):70-75.

8) Aggeli C, Felekos I, Angelis A, et al. Dobutamine stress echo in diabetics: Changes in prognosis according to appropriateness criteria indication. Int J Cardiol 2016; 214:207208.

9) Kwong RY, Sattar $\mathrm{H}, \mathrm{Wu} \mathrm{H}$, et al. Incidence and prognostic implication of unrecognized myocardial scar characterized by cardiac magnetic resonance in diabetic patients without clinical evidence of myocardial infarction. Circulation 2008; 118(10):10111020.

10) Bauters $C$, Deneve $M$, Tricot $O$, et al. Prognosis of patients with stable coronary artery disease (from the CORONOR study) Am J Cardiol 2014; 113(7):1142-1145.

11) Raggi P, Bellasi A, Ratti C. Ischemia imaging and plaque imaging in diabetes: complementary tools to improve cardiovascular risk management. Diabetes Care 2005; 28: 2787- 2794.

12) Stein JH, Korcarz CE, Hurst RT, et al. Use of carotid ultrasound to identify subclinical vascular disease and evaluate cardiovascular disease risk: a consensus statement from the American Society of Echocardiography CarotidIntima-Media Thickness Task Force. Endorsed by the Society for Vascular Medicine. J Am Soc Echocardiogr 2008; 21: 93- 111.

13) Faglia E, Favales F, Calia $P$, et al. Cardiac events in 735 type 2 diabetic patients who underwent screening for unknown asymptomatic coronary heart disease: 5- year follow-up report from the Milan Study on Atherosclerosis and Diabetes (MiSAD). Diabetes Care 2002; 25:2032-36.

14) Muhlestein J. B, Loppé D. L, Lima J. A. $\mathrm{C}$, et al. "Effect of screening for coronary artery disease using CT angiography on mortality and cardiac events in high-risk patients with diabetes. The FACTOR-64 randomized clinical trial," JAMA 2014; 312(21): 2234-2243.

15) Wackers F, Young L, Inzucchi S, et al. Detection of Ischemia in Asymptomatic Diabetics Investigators. Detection of silent myocardial ischemia in asymptomatic diabetic subjects: the DIAD study. Diabetes Care 2004; 27:1954-1961.

16) Mitsushashi N, Onurna T, Kubo S, et al. Coronary Artery Disease and Carotid Artery Intima-Media Thickness in Japanese Type 2 Diabetic Patients. Diabetes Care 2002; 25:1308-1312. 
17) Cheng $\mathrm{X}$, Zhou $\mathrm{Y}$, Jin $\mathrm{Y}$, et al. Intima-medial thickness homogeneity in the common carotid artery: Measurement method and preliminary clinical study. J Clin Ultrasound 2012; 40(9), 559-565.

18) Johnson HM, Douglas PS, Srinivasan $\mathrm{SR}$, et al. Predictors of carotid intima-media thickness progression in young adults: the Bogalusa Heart Study. Stroke 2007; 38(3):900905.

19) Kafetzakis A, Kochiadakis G, Laliotis A, et al. Association of subclinical wall changes of carotid, femoral, and popliteal arteries with obstructive coronary artery disease in patients undergoing coronary angiography. Chest 2005; 128(4):2538-2543.

20) Kablak-Ziembicka A, Tracz W, Przewlocki T, et al. Association of increased carotid intima-media thickness with the extent of coronary artery disease. Heart 2004; 90(11):1286-1290.

21) Holland Z, Ntyintyane LM, Raal FJ, et al. Carotid intima-media thickness is a predictor of coronary artery disease in South African black patients. Cardiovasc J Afr 2009; 20(4): 237-239.

22) Greenland P, Alpert JS, Beller GA. ACCF/AHA guideline for assessment of cardiovascular risk in asymptomatic adults: executive summary: a report of the American College of Cardiology Foundation/ American
Heart Association Task Force on Practice Guidelines. Circulation 2010; 122:2748-2764.

23) Oei HH, Vliegenthart R, Hak AE, et al. The association between coronary calcification assessed by electron beam computed tomography and measures of extra coronary atherosclerosis: the Rotterdam Coronary Calcification Study. J Am Coll Cardiol 2002; 39:1745-1751.

24) Ahmadvazir S, Zacharias K, Shah BN, et al. Role of simultaneous carotid ultrasound in patients undergoing stress echocardiography for assessment of chest pain with no previous history of coronary artery disease. Am Heart J 2014; 168:229-236.

25) Hallerstam S, Larsson PT, Zuber E, et al. Carotid atherosclerosis is correlated with extent and severity of coronary artery disease evaluated by myocardial perfusion scintigraphy. Angiology 2004; 55:281-288. 